\title{
Carcinoembryonic Antigen Measurement
}

National Cancer Institute

\section{Source}

National Cancer Institute. Carcinoembryonic Antigen Measurement. NCI Thesaurus.

Code C81983.

The determination of the amount of carcinoembryonic antigen present in a sample. 